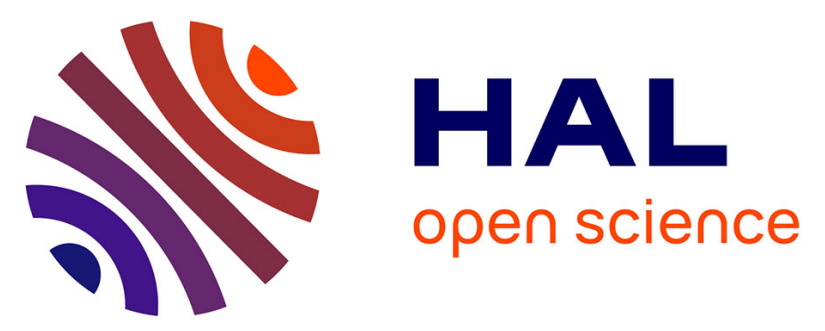

\title{
Synthesis and grafting of a thiourea-based chelating agent on SH-SAW transducers for the preparation of thin films sensitive to heavy metals
}

Laurent Fertier, Marc Rolland, Thierry Thami, Michel Persin, Céline Zimmermann, Jean-Luc Lachaud, Dominique Rebière, Corinne Dejous, Eric

Bêche, Marc Cretin

\section{To cite this version:}

Laurent Fertier, Marc Rolland, Thierry Thami, Michel Persin, Céline Zimmermann, et al.. Synthesis and grafting of a thiourea-based chelating agent on SH-SAW transducers for the preparation of thin films sensitive to heavy metals. Materials Science and Engineering: C, 2009, 29 (3), pp.823-830. 10.1016/j.msec.2008.07.032 . hal-00354198

\section{HAL Id: hal-00354198 https://hal.science/hal-00354198}

Submitted on 27 Jan 2021

HAL is a multi-disciplinary open access archive for the deposit and dissemination of scientific research documents, whether they are published or not. The documents may come from teaching and research institutions in France or abroad, or from public or private research centers.
L'archive ouverte pluridisciplinaire HAL, est destinée au dépôt et à la diffusion de documents scientifiques de niveau recherche, publiés ou non, émanant des établissements d'enseignement et de recherche français ou étrangers, des laboratoires publics ou privés. 


\title{
Synthesis and grafting of a thiourea-based chelating agent on SH-SAW
}

\section{transducers for the preparation of thin films sensitive to heavy metals}

\author{
L. Fertier ${ }^{\mathrm{a}}$, M. Rolland ${ }^{\mathrm{a}}$, T. Thami ${ }^{\mathrm{a}}$, M. Persin ${ }^{\mathrm{a}}$, C. Zimmermann ${ }^{\mathrm{b}}$, J-L. Lachaud ${ }^{\mathrm{b}}$, D. Rebière ${ }^{\mathrm{b}}$,
} C. Déjous ${ }^{\mathrm{b}}, \mathrm{E}^{\mathrm{E}}$ Bêche $^{\mathrm{c}}$ and M. Cretin ${ }^{\mathrm{a}}$

\author{
a Institut Européen des Membranes, Université Montpellier 2 - ENSCM - CNRS, \\ Place Eugène Bataillon, CC047, 34095 Montpellier Cedex 5, France \\ b Laboratoire de l'Intégration du Matériau au Système (IMS) - Université de Bordeaux - ENSEIRB, \\ 351 cours de la Libération, 33405, Talence Cedex, France \\ ${ }^{c}$ Laboratoire PROcédés, Matériaux et Energie Solaire, CNRS-PROMES-SASI, \\ 7 rue du four solaire, 66120 Font-Romeu Cedex, France
}

\begin{abstract}
The surface functionalization of guided SH-SAW (Shear Horizontal - Surface Acoustic Wave) transducers was carried out to prepare layers sensitive to heavy metals. To this purpose, a thiourea molecule acting as a chelating agent was grafted on the top-layer of the transducer. This covalent immobilization was obtained by amide bonds through primary amine groups immobilized on the device by the chemisorption of the 3-aminopropyltriethoxysilane (APTES). The physicochemical characterizations of the multi-layer systems were done by ellipsometry, wettability studies, UV-visible spectroscopy and XPS and shown that the grafting of the molecule is achieved through the preparation of nanometric films. The acoustic properties of the devices were mainly related to the nanometric thickness of the layers, which proved chemisorption of APTES was an efficient method to prepare a chemical acoustic sensor. The possibility to use such a functionalized layer in a microfluidic analysis system was shown by first attempts of sensitivity in liquid media.
\end{abstract}

Keywords: Thin film, Surface functionalization, Amide coupling, Surface Acoustic Wave,

\footnotetext{
* Corresponding author: Tel.: +33(0)4676134 10; fax: +33(0)467042820.

E-mail address: marc.cretin@iemm.univ-montp2.fr
} 


\section{Introduction}

Chemical sensors constitute a cheap and efficient way to avoid expensive campaigns of sampling and systematic analyses in laboratory. A chemical sensor is basically composed of a material able to detect changes in the environment (the "sensitive" material) and a transducer able to translate this change into a quantifiable signal. Among others, detection of mass variation is one of the simplest methods. SH-SAW (Shear Horizontal - Surface Acoustic Wave) based sensors also named Love's wave sensors are good candidates because they are sensitive to tiny mass variations of a substrate deposited onto their surface [1,2]. Then they offer a high sensitivity, and moreover, their production cost is low because they can be made of high quantity by the microelectronic technology [3]. Nevertheless, whereas they have been used for several years in gas sensing field [4], their development in liquid media is more recent and especially devoted to the bioanalysis [5]. At this time and from our acknowledge, works devoted to heavy metals detection by acoustic waves are only based on the use of Quartz Crystal Microbalances (QCM) and Bulk Acoustic Waves (BAW) but not on SH-SAW devices. For the development of heavy metals sensitive QCM devices, the main approach developed in the literature is based on the interaction between the targets (i.e. $\left.\mathrm{Pb}^{2+}, \mathrm{Hg}^{2+}, \mathrm{Cd}^{2+}\right)$ in solution and a sensitive molecule [6] or biomolecule $[7,8]$ immobilized onto the gold electrode of the QCM surface. The immobilization is obtained either by self-assembled monolayers (thiolate bonds) [6,8] or by reticulation through glutaraldehyde [7].

To prepare layers sensitive to heavy metals (especially $\mathrm{Pb}^{2+}$ and $\mathrm{Cd}^{2+}$ ) in aqueous medium we develop here a new approach based on SH-SAW transducer modified by the grafting of a chelating molecule (i.e. a thiourea based molecule) sensitive to $\mathrm{Pb}^{2+}$ and $\mathrm{Cd}^{2+}$. The complexation properties in solution of the thiourea based molecule have been previously described for the heavy metals detection with ionic selective electrodes based on liquid membranes [9]. But a method for the surface immobilization of thiourea in sensing application as SAW has never been developped. Therefore, a thiourea molecule bearing carboxylic group was synthesized for the surface modification of aminosilane layers. The covalent immobilization by using silane coupling agents is 
widely used for surface modification $[10,11]$ because it provides strong surface attachment with the silica surface via siloxane groups. In particular the use of the 3-aminopropyltriethoxysilane (APTES) to give aminosilane layer is very attractive because it has been widely used for subsequent immobilization of molecules or biomolecules via a reaction with the reactive primary amino groups [12-14]. Among the various methods used for the functionalization of silica surfaces with APTES [14-18], the silanization reaction in anhydrous organic solvent, such as toluene, has the advantage to give homogeneous and stable thin multilayers with a coverage equivalent to one to a few monolayers (determined by ellipsometry) depending upon the reaction time and temperature $[12,13,14,15,17]$.

The first step of the preparation of the sensitive layer is then the chemical immobilization of primary amine functions on the transducer silica top-layer (Fig. 1 step 1) and the second operation is the chemical linkage of the chelating agent through an amide bond between a carboxylate function of the ligand and the primary amine on the transducer top-layer (Fig. 1 step 2). The novelty of this approach is mainly the coupling of a very sensitive transducer in flow conditions (i.e. the SH-SAW device) with a chemical molecule (i.e. the thiourea based molecule) presenting a high and easily controllable affinity to heavy metals in solution. Moreover, to achieve a high stability of the chelating molecule immobilization and to minimize the thickness of the intermediate grafting layer (sine qua none condition to get a high sensitivity), we use an aminopropylsiloxane to generate primary amines on the device surface because of the high stability of siloxane bonds and the low thickness of such a layer.

The details of the synthesis of the thiourea ligand and its ability to bind heavy metals in solution are described in the first part of the paper. The preparation of the aminopropyltriethoxysilane layer, the grafting of the thiourea by amide bond and its characterization (ellipsometry, wettability, UV-visible spectroscopy and XPS) are presented in the 
second part. The electrical characterizations of the transducer equipped with the functionalized layers are shown and first attempts of film sensitivity using a microfluidic system are discuted in the third section.

\section{Experimental set-up}

\subsection{The piezoelectric detection system}

Guided Shear Horizontal -Surface Acoustic Wave (SH-SAW) sensors are based on a piezoelectric delay line, with interdigital transducers (IDT) on a quartz substrate to generate and to receive an elastic wave [19]. Depending on the crystallographic orientation of the quartz, a pure shear horizontal wave is generated, which enables the use of the sensor in liquid media. A guiding layer is deposited on this device in order to confine the acoustic energy at the near surface of the sensor and so to provide a high sensitivity. When the target is caught by the sensitive layer (deposited on the guiding layer [20]), the acoustic wave propagation is disturbed resulting in a decrease of its phase velocity due to the mass addition (i. e. mass loading effect).

Guided SH-SAW devices are produced by the LAAS (Laboratoire d'Analyses et d'Architectures des Systèmes, Toulouse, France). They consisted of an AT-cut quartz substrate (The Roditi International Corporation Ltd., London, England), covered by a $\mathrm{SiO}_{2}$ guiding layer deposited by plasma enhanced chemical vapor deposition. The interdigitated electrodes (IDTs) consisted of 44 finger pairs of $20 \mathrm{~nm}$ titanium (Ti) and $70 \mathrm{~nm}$ of gold (Au) with a wavelength $\lambda$ equal to $40 \mu \mathrm{m}$, prepared by using a lift-off process [19]. The IDTs aperture was $39 \lambda$ and the propagation path between the IDTs center was $210 \lambda$. The $\mathrm{SiO}_{2}$ guiding layer thickness is about $4 \mu \mathrm{m}$ resulting in a synchronous frequency of $118.1 \mathrm{MHz}$.

\subsection{Chemicals}

All reagents and solvents were supplied from commercial sources and were of analytical grade. Milli-Q water was used to prepare aqueous solutions. 
${ }^{1} \mathrm{H}$ NMR spectra were recorded at $300 \mathrm{MHz}$ using a Bruker Avance instrument (Bruker Germany). For ${ }^{1} \mathrm{H}$ NMR spectra recorded in $\mathrm{CDCl}_{3}$ chemical shifts are quoted in parts per million and are referenced to the residual solvent peak. The following abbreviations are used: s, singlet; $d$, doublet; t, triplet; q, quartet; m, multiplet; br, broad. Coupling constants are reported in Hertz (Hz). Ionic electrospray mass spectroscopy was performed with a Waters-Micromass spectrometer (Manchester, England) in negative acquisition ESI-MS (-).

\subsection{Chemisorption of the 3-aminopropyltriethoxysilane (APTES)}

The amine functionalization of the transducer, needed for the thiourea grafting, was done by chemisorption of the 3-aminopropyltriethoxysilane (APTES) $[12,13,15]$ on the silanol surface groups of the silica guiding layer.

Prior to thin layer deposition, each surface was cleaned for $1 \mathrm{~h}$ in hot «piranha » solution (solution of $30 \% \mathrm{H}_{2} \mathrm{O}_{2}$ in concentrated $\mathrm{H}_{2} \mathrm{SO}_{4}$ ), rinsed several times with high-purity water and dried in a stream of nitrogen. The chemisorption was obtained by dipping the substrates in a $2.5 \%$ solution of APTES in toluene for 45 minutes under reflux. The substrates were then rinsed twice with dichloromethane and once with ethanol and dried in a stream of nitrogen. The chemisorption of APTES was done on the transducers but also on p-type silicon (100) wafers (one side polished) for ellipsometry characterizations

\subsection{Organic synthesis and characterization}

\subsubsection{Synthesis of the ligand}

The 3,3-disubstituted 1-furoylthioureas have the properties to form coordination complexes with heavy metals as shown by Otazo-Sánchez et al. [9]. Based on this model, we have synthesized a derivative able to complex $\mathrm{Cd}^{2+}$ and to be grafted on the amino functionalized surface. The chelating agent $\mathbf{( 5 )}$ was then synthesized $[21,22]$ in four steps (Scheme 1). The ion-selective part of the thiourea (methyl 4-(benzylamino)benzoyl (2)) was synthesized [23] from methyl 4- 
aminobenzoate to get a free carboxylic function for the grafting. The $\alpha$-part of the thiourea was constituted of a furoyl group. Commercial 2-furoyl chloride was used in one-pot addition reaction through compound (2) to yield. The thiourea (4) was not ready to be grafted on the amino group surface. To obtain the free carboxylic acid (5) the methyl ester was then hydrolyzed in the last step of the strategy.

\section{Synthesis details:}

Methyl 4-(benzylamino)benzoyl (2):

Benzaldehyde (3.36 mL, $3.51 \mathrm{~g}, 33.08 \mathrm{mmol}$ ) was added to a magnetically stirred solution of methyl 4-aminobenzoyl (3) (5.00 g, $33.08 \mathrm{mmol})$ in absolute ethanol (20 mL). After 15 minutes stirring at room temperature a mixture of sodium borohydride $(2.08 \mathrm{~g}, 33.08 \mathrm{mmol})$ and boric acid (2.05 g, $33.08 \mathrm{mmol})$ was slowly added. The reaction mixture was vigorously stirred for 45 minutes and then poured into a $\mathrm{NaHCO}_{3}$ saturated solution $(100 \mathrm{~mL})$. After concentration under reduced pressure, the residue was extracted with ethyl acetate $(3 \times 15 \mathrm{~mL})$ and over $\mathrm{Na}_{2} \mathrm{SO}_{4}$. After filtration and solvent removal the residue was purified on a silica gel chromatography column $\left(\mathrm{CH}_{2} \mathrm{Cl}_{2}, 1 \%\right.$ $\mathrm{MeOH}, 0,5 \% \mathrm{AcOH})$ to afford the desired product $(6.78 \mathrm{~g}, 85 \%)$ as a white solid: ${ }^{1} \mathrm{H} \mathrm{NMR}\left(\mathrm{CDCl}_{3}\right)$ $\delta_{\mathrm{H}} 3.73\left(3 \mathrm{H}, \mathrm{s}, \mathrm{CH} H_{3}\right), 3.78(1 \mathrm{H}, \mathrm{sl}, \mathrm{NH}), 4.34\left(2 \mathrm{H}, \mathrm{d}, J 6, \mathrm{CH}_{2}\right), 6.62(2 \mathrm{H}, \mathrm{d}, J 8.4,2 \times \mathrm{CH}(\mathrm{Ph})-\mathrm{C}-$ N), $7.30(5 \mathrm{H}, \mathrm{m}, \mathrm{CH}(\mathrm{Bz})), 7.70(2 \mathrm{H}, \mathrm{d}, J 8.4 \mathrm{~Hz}, 2 \times \mathrm{CH}(\mathrm{Ph})-\mathrm{C}) ; \delta_{\mathrm{C}}\left(300 \mathrm{MHz}, \mathrm{CDCl}_{3}\right) 47.15$ $\left(\mathrm{CH}_{2}\right), 51.04\left(\mathrm{CH}_{3}-\mathrm{O}\right), 111.17(\mathrm{CH}=\mathrm{C}-\mathrm{C}=\mathrm{O}), 118.11(2 \times \mathrm{CH}(\mathrm{Ph}), 126.95(\mathrm{CH}(\mathrm{Bz})), 128.28$ $(\mathrm{CH}(\mathrm{Bz})), 131.08(2 \times \mathrm{CH}(\mathrm{Ph})), 137.91\left(\mathrm{CH}=\mathrm{C}-\mathrm{CH}_{2}\right), 151.33(\mathrm{CH}=\mathrm{C}-\mathrm{NH}), 166.85(\mathrm{O}-\mathrm{C}=\mathrm{O})$.

Methyl 4-\{benzyl[(2-furoylamino)carbonothioyl]amino\} benzoate (4):

To a solution of 2-furoyl chloride (3) $(3.15 \mathrm{~mL}, 4.17 \mathrm{~g}, 32 \mathrm{mmol})$ in dried acetone (30 mL) was added potassium thiocyanate $(3.79 \mathrm{~g}, 39 \mathrm{mmol})$. After 1 hour under reflux, methyl 4(benzylamino)benzoate (2) $(7.7 \mathrm{~g}, 32 \mathrm{mmol})$ was slowly added and the whole was stirred under reflux for 30 minutes. Acetone was evaporated under vacuum and cold ethanol $(10 \mathrm{~mL})$ was added 
to keep at $0^{\circ} \mathrm{C}$ overnight. After filtration and solvent removal the residue was dissolved in ethyl acetate $(100 \mathrm{~mL})$ and washed with a $1 \mathrm{~N} \mathrm{Na}_{2} \mathrm{CO}_{3}$ solution $(2 \mathrm{x} 25 \mathrm{~mL})$. The solution was then dried over $\mathrm{MgSO}_{4}$ and concentrated in vacuum to afford a yellowish solid. The solid was then purified by chromatography on silica gel $\left(\mathrm{CH}_{2} \mathrm{Cl}_{2}\right)$ to give pure (4) $(3.5 \mathrm{~g}, 28 \%)$ as yellow crystals. $\delta_{\mathrm{H}}(300$ $\left.\mathrm{MHz} \mathrm{CDCl}_{3}\right) 3.77\left(3 \mathrm{H}, \mathrm{s}, \mathrm{CH}_{3}\right), 5.62\left(2 \mathrm{H}, \mathrm{s}, \mathrm{CH}_{2}\right), 6.58(1 \mathrm{H}, \mathrm{dd}, J 1.8$ and 3.6, $\mathrm{CH}=\mathrm{CH}-\mathrm{CH}), 7.23-$ $7.40(9 \mathrm{H}, \mathrm{m}), 7.81(2 \mathrm{H}, \mathrm{m}), 7.83(1 \mathrm{H}, \mathrm{sl}, \mathrm{NH}) . \delta_{\mathrm{C}}\left(300 \mathrm{MHz}, \mathrm{CDCl}_{3}\right) 51.77\left(\mathrm{O}-\mathrm{CH}_{3}\right), 59.92\left(\mathrm{CH}_{2}\right)$, $112.33(\mathrm{C}=\mathrm{CH}=\mathrm{C}), 116.93(\mathrm{CH}=\mathrm{CH}-\mathrm{C}), 125.29-130.03(\mathrm{C}(\mathrm{Ar})), 134.64\left(C-\mathrm{CH}_{2}\right), 144.85(\mathrm{O}-$ $\mathrm{CH}=\mathrm{CH}), 145.42(\mathrm{O}-\mathrm{C}=\mathrm{CH}), 147.45(\mathrm{C}=\mathrm{C}-\mathrm{N}), 151.72(\mathrm{~N}-\mathrm{C}=\mathrm{O}), 165.56(\mathrm{O}-\mathrm{C}=\mathrm{O}), 179.49(\mathrm{C}=\mathrm{S})$; ESI-MS (-) 393 ( $\left.\mathrm{M}^{-}{ }^{-}\right)$.

4-\{benzyl[(2-furoylamino)carbonothioyl]amino\}benzoic acid (5):

A solution of $1 \mathrm{M} \mathrm{NaOH}(10.2 \mathrm{~mL}, 10.2 \mathrm{mmol})$ was slowly added to a stirred solution of (4) $(2 \mathrm{~g}, 5.1 \mathrm{mmol})$ in methanol $(15 \mathrm{~mL})$ at $0^{\circ} \mathrm{C}$. After 4 hours stirring the reaction mixture was concentrated in vacuum and the residue was washed with ethyl acetate $(2 \times 10 \mathrm{~mL})$. The aqueous layer was then acidified by $1 \mathrm{M} \mathrm{HCl}$ until $\mathrm{pH}=2$. The precipitate was filtered off and recrystallized in ethyl acetate to give (5) $(1.4 \mathrm{~g}, 83 \%)$ as yellow crystals. $\lambda_{\max }\left(\mathrm{CH}_{2} \mathrm{Cl}_{2}\right) / \mathrm{nm} 282\left(\varepsilon / \mathrm{dm}^{3} \mathrm{~mol}^{-1} \mathrm{~cm}^{-1}\right.$ $15200) ; \delta_{\mathrm{H}}\left(300 \mathrm{MHz}, \mathrm{CDCl}_{3}\right) 5.59\left(2 \mathrm{H}, \mathrm{s}, \mathrm{CH}_{2}\right), 6.46(1 \mathrm{H}, \mathrm{dd}, J 1.8,3.6 \mathrm{~Hz}, \mathrm{CH}=\mathrm{C} H-\mathrm{CH}), 7.09$ $(2 \mathrm{H}, \mathrm{m}), 7.27-7.47(7 \mathrm{H}, \mathrm{m}), 8.01(2 \mathrm{H}, \mathrm{m}), 8.82(1 \mathrm{H}, \mathrm{sl}, \mathrm{NH}), 10.70(1 \mathrm{H}, \mathrm{sl}, \mathrm{OH}) ; \delta_{\mathrm{C}}(300 \mathrm{MHz}$, $\left.\mathrm{CDCl}_{3}\right) 60.05\left(\mathrm{CH}_{2}\right), 112.38(\mathrm{C}=\mathrm{CH}=\mathrm{C}), 117.16(\mathrm{CH}=\mathrm{CH}-\mathrm{C}), 125.30-130.66(C(\mathrm{Ar})), 134.54(C-$ $\left.\mathrm{CH}_{2}\right), 144.95(\mathrm{O}-\mathrm{CH}=\mathrm{CH}), 148.32(\mathrm{O}-\mathrm{C}=\mathrm{CH}), 151.77(\mathrm{C}=\mathrm{C}-\mathrm{N}), 162.92(\mathrm{~N}-\mathrm{C}=\mathrm{O}), 170.34(\mathrm{HO}-$ $C=\mathrm{O}), 179.80(\mathrm{C}=\mathrm{S})$; ESI-MS (-) $379\left(\mathrm{M}^{-}\right)$; Anal. Calculated (\%) for $\mathrm{C}_{20} \mathrm{H}_{16} \mathrm{~N}_{2} \mathrm{O}_{4} \mathrm{~S}: \mathrm{C}, 63.14 ; \mathrm{H}$, 4.24; N, 7.36; S, 8.43. Found (\%): C, 63.14; H, 5.34; N, 6.39; S, 7.93.

\subsubsection{Polarographic characterization}

The complexation properties of the ligand toward $\mathrm{Pb}^{2+}$ and $\mathrm{Cd}^{2+}$ were determined by a polarographic study using a differential pulse polarograph (Radiometer POL 150, software: 
TraceMaster 5, Radiometer Analytical - France) equipped with a static mercury falling drops electrode (growth time: $0.5 \mathrm{~s}$, echelon time: $1 \mathrm{~s}$, echelon amplitude: $5 \mathrm{~ms}$, pulse time: $40 \mathrm{~ms}$, pulse amplitude: $-25 \mathrm{mV}$ ), an $\mathrm{Ag} / \mathrm{AgCl}$ reference electrode and a Pt wire counter electrode. To know the stoechiometry of the complexes and their stability constants toward $\mathrm{Pb}^{2+}$ and $\mathrm{Cd}^{2+}$, the reductive potential of the cation in presence of various ligand concentrations was determined. The measurement was carried out between $-0.22 \mathrm{~V}$ and $-1.0 \mathrm{~V}$ for $\mathrm{Pb}^{2+}$ and between $-0.45 \mathrm{~V}$ and $-1.0 \mathrm{~V}$ for $\mathrm{Cd}^{2+}$. All potentials were given vs. $\mathrm{Ag} / \mathrm{AgCl}$.

Aliquots of a concentrated solution of the chelating agent were added to a solution of $\mathrm{Cd}^{2+}$ or $\mathrm{Pb}^{2+}\left(5.10^{-5} \mathrm{M}\right)$ in $\mathrm{KNO}_{3}(0.1 \mathrm{M})$ to obtain a rise of concentration from $2.10^{-3} \mathrm{M}$ to $1.4 .10^{-2} \mathrm{M}$ (chelate excess). The shift of the reductive potential of $\mathrm{Cd}^{2+}$ or $\mathrm{Pb}^{2+}$ was measured as a function of the chelating agent concentration which allows calculating the stoechiometry of the complex and its stability constant [24]. These calculations were based on the Nernst's law (Eqn. 1) and on the expression of the stability constant of the complex $K$ (Eqn. 2), where $E_{1 / 2}$ is the half-wave potential of the cation $\mathrm{M}^{\mathrm{n}+}\left(\mathrm{Cd}^{2+}\right.$ or $\left.\mathrm{Pb}^{2+}\right) ; E^{\circ}$ its apparent standard potential ; $n$ the charge (i.e. $n=2$ for cadmium and lead) ; $\left[M L_{m}\right],\left[M^{n+}\right]$ and $[L]$ the molar concentrations of the complex, the free cation and the ligand, respectively; $m$ the complex stoechiometry. In presence of an excess of ligand and assuming that the apparent standard potentials of the free cation and of the complex are identical, we obtained the equation (Eqn. 3), where $\Delta E_{1 / 2}$ is the difference between the half-wave potential of the complex and the free cation. The stoechiometry coefficient $m$ was then calculated from the slope value of the representation of $\Delta E_{1 / 2}$ vs $(-\log [L])$ and the stability constant value $p K$ was determined by the $y$-intercept.

$$
\begin{aligned}
& E_{1 / 2}=E^{\circ}+2.3 \times \frac{R T}{n F} \times \log \left[M^{n+}\right] \\
& K=\frac{\left[M L_{m}\right]}{\left[M^{n+}\right] \times[L]^{m}} \\
& \Delta E_{1 / 2}=2.3 \times \frac{R T}{n F} \times(m \times-\log [L]+p K)
\end{aligned}
$$




\subsection{Grafting of the sensitive thiourea on the primary amine functionalized surfaces}

According to the following method $[25,26]$, preliminary activation of the acid function was used to link the sensitive molecule to the amino group on the surface (Scheme 2). To a solution of 4-\{benzyl[(2-furoylamino)carbonothioyl] amino\}benzoic acid (5) (57 $\mathrm{mg}, 0.15 \mathrm{mmol}$ ) in dichloromethane $(15 \mathrm{~mL})$ was added N,N-diisopropylethylamine DIEA $(105 \mu \mathrm{L}, 6.1 \mathrm{mmol})$, (benzotriazol-1-yloxy)tris(dimethylamino)phosphonium hexafluorophosphate BOP (73 mg, 1.65 mmol), 1-hydroxybenzotriazole HOBt $(22 \mathrm{mg}, 1.63 \mathrm{mmol})$ and the mixture reaction was stirred for 20 minutes at room temperature. The devices were then immersed in the previous solution for overnight at room temperature. The grafted surface was rinsed with ethanol and dried in a stream of nitrogen.

\subsection{Physico-chemical characterizations of the multi-layer}

\subsubsection{Amine functionalization}

The determination of the primary amines immobilized via APTES on the surfaces was carried out by the Kaiser's test and by XPS. The so-called Kaiser's test is a rapid and sensitive method for the qualitative and quantitative determination of free amino groups [27]. The technique involves the reaction between a free amine and the ninhydrin under carefully controlled conditions, which leads to the formation of a dark-blue chromophore $(570 \mathrm{~nm})$. For that two reagents were prepared: reagent $\mathrm{A}$ contained $40 \mathrm{~g}$ of phenol in absolute ethanol $(10 \mathrm{~mL})$, mixed with a $\mathrm{KCN}$ solution $(2 \mathrm{~mL})$ diluted with pyridine $(100 \mathrm{~mL})$, and reagent $\mathrm{B}$ contained $2.5 \mathrm{~g}$ of ninhydrin diluted in absolute ethanol $(50 \mathrm{~mL})$. The primary amine functionalized surfaces were plunged into a mixture of both reagents $(200 \mu \mathrm{L}$ of reagent $\mathrm{A}$ and $50 \mu \mathrm{L}$ of reagent $\mathrm{B})$ and the system was heated at $100{ }^{\circ} \mathrm{C}$ for 10 minutes. Afterwards, the resulting solution became dark-blue in presence of terminal amino groups on the surface and the determination of the absorbance of the solution lead to the calculation of the surface density of terminal amino groups after a calibration stage using the Beer-Lambert law. 
XPS analyses were performed using a SIA Riber Cameca UHV device operating at a pressure of $10^{-9}$ Torr. The kinetic energy of the photoelectrons was measured using a Riber Cameca MAC 2 spectroscopic two-stage spectrometer. The photoelectron emission spectra were recorded using an $\mathrm{Al}-\mathrm{K} \alpha(\mathrm{h} v=1486.6 \mathrm{eV})$ non monochromatized source $(600 \mathrm{~W})$. The angle between the $\mathrm{X}$ ray direction and the emitted electron direction was $60^{\circ}$. The analyzed area was about $25 \mathrm{~mm}^{2}$. The analyzer resolution was fixed at $1 \mathrm{eV}$. Spectrometer energy calibration was made using the $\mathrm{Au} 4 \mathrm{f}^{7 / 2}$ $(83.9 \pm 0.1 \mathrm{eV})$ and $\mathrm{Cu} 2 \mathrm{p}^{3 / 2}(932.8 \pm 0.1 \mathrm{eV})$ photoelectron lines. XPS spectra were recorded in direct $\mathrm{N}(\mathrm{Ec})$. If the background signal was removed, it was made using the Shirley method [28]. The surface atomic concentrations were determined from photoelectron peaks areas using the atomic sensitivity factors reported by Scofield [29] or using our atomic sensitivity factors determined for reference samples and taking account the transmission function of the analyzer. The samples under study produced charging shifts (about $+1 \mathrm{eV}$ in binding energy). The binding energy scale was established by referencing the $\mathrm{C}$ 1s value of adventitious carbon $(285 \mathrm{eV})[30,31]$. The photoelectron peaks were analyzed by Gaussian/Lorentzian peak fitting. The fixed full width at half maximum FWHM and the fixed positions of the components were similar to those collected on our reference samples.

\subsubsection{Layers thickness}

The thickness of the APTES layers deposited on the silicon wafers was determined by ellipsometry (SD2300 ellipsometer, Plasmos - Germany) equipped with a $632.8 \mathrm{~nm}$ He-Ne laser. The incidence angle was $70^{\circ}$. The thickness of the silicon oxide native layer on the wafer was about $1.8 \mathrm{~nm}$ and was measured separately assuming the refraction indice for $\mathrm{SiO}_{2}$ and for $\mathrm{Si}$ was $\mathrm{n}=$ 1.457 and $n=3.871-0.016 \mathrm{i}$, respectively. To calculate the thickness, we assumed the refractive index of the bilayer $\mathrm{SiO}_{2}$ /APTES was the same as the refractive index of the $\mathrm{SiO}_{2}$ (i.e. $\left.\mathrm{n}=1.457\right)$. Indeed, the reported refractive index of the bulk APTES polymer $(n=1.427)$ [13] was closed to $\mathrm{SiO}_{2}$ (1.457). The values were obtained by averaging three measurements. 


\subsubsection{Wettability study}

Water contact angle measurements were carried out to characterize the hydrophobicity of the multi-layer assemblage at different stages. Contact angle was measured by the deionized water drop method with a Kruss apparatus G2 (Kruss - Germany).

\subsection{Devices characterization}

Guided SH-SAW sensors are mainly sensitive to perturbations due to mass addition on the sensitive layer which lead to a decrease of the phase velocity of the wave. To improve measurement resolution, Love wave devices were inserted in an oscillation loop with an electronic feedback (Fig. 2). The oscillator had to satisfy the Barkhausen conditions to provide oscillation frequency, that is to say: an open loop gain greater or equal to 1 and a zero open loop phase for the resulting oscillation frequency [32]. Whereas the electronic feedback had a constant phase, a decrease of the sensor phase resulted in an oscillation frequency shift.

The short-term stability of oscillators impacts the detection threshold of the guided SH-SAW sensor. These oscillators reach a short-term stability lower than $1 \mathrm{~Hz} / \mathrm{s}$ at $119.6 \mathrm{MHz}$ working frequency. The stability was controlled before mounting the acoustic transducers in oscillator configuration by electrical tests made with a network analyzer (ANRITSU VNA MS4623B 10 $\mathrm{MHz} / 6 \mathrm{GHz}, \mathrm{USA}$ ) in order to verify the compatibility between electrical characteristics and oscillator condition.

The acoustic measurements in liquid environment were carried out at $25^{\circ} \mathrm{C}$ (thermostatic sand bath) in a micro-cell $(\mathrm{V}=500 \mu \mathrm{L})$ at a flow rate of $100 \mu \mathrm{L} / \mathrm{min}$. The first step was the circulation of deionized water until the stabilization of the frequency (drift $<60 \mathrm{~Hz} \cdot \mathrm{mn}^{-1}$ ). The second step was the circulation of a cadmium solution $(0.01 \mathrm{M})$. After the frequency stabilization the cadmium solution was substituted by deionized water to compare the new stabilized frequency with the initial frequency. Both steps were repeated twice. To confirm that the frequency decrease is linked to $\mathrm{Cd}^{2+}$ complexation at the transductor's functionalized sensitive surface, a solution of a strong chelating 
agent (i.e ethylenediaminetetraacetic acid -EDTA- 0.01 M) was circulated to remove the cadmium caught. After the frequency stabilization, the EDTA solution was replaced by deionized water, as previously done, to get a stable value. The operation with EDTA was repeated twice for an optimal decomplexation.

\section{Results and discussion}

\subsection{Complexing properties of the chelating agent}

The polarographic study was carried out to show the chelating activity of the ligand and to determine the complexation constants with cadmium and lead. As shown in Figure 3 for $\mathrm{Cd}^{2+}$, the reductive potential of the complex is inferior to the one of the free cation (because the energy needed to reduce the complex is higher). The shift between the reductive potential of the free cation and the complex $\left(\Delta \mathrm{E}_{1 / 2}\right)$ has been recorded as a function of the ligand concentration (curves not shown). As expected by the theory (Eqn. 3) the evolution of $\Delta \mathrm{E}_{1 / 2} v s-\log [\mathrm{L}]$ was linear in both cases $\left(\Delta E_{1 / 2}=0.0706(-\log [L])-0.3224\left(\mathrm{r}^{2}=0.965\right)\right.$ and $\Delta E_{1 / 2}=0.0535(-\log [L])-0.3588\left(\mathrm{r}^{2}\right.$ $=0.830$ ) for $\mathrm{Cd}^{2+}$ and $\mathrm{Pb}^{2+}$, respectively). According to Eqn. 3 the slope values were related to the formation of a complex of the 2:1 type ( 2 moles of ligand for 1 mole of metal) between the ligand (5) and $\mathrm{Cd}^{2+}(m=2.3)$ or $\mathrm{Pb}^{2+}(m=1.8)$ and the conditional stability constants ( $K$ calculated from the values of the $\mathrm{y}$-intercepts were $10^{11}$ (at $\mathrm{pH}$ 8.0) and $10^{12}$ (at $\mathrm{pH} 10.0$ ) for $\mathrm{Cd}^{2+}$ and $\mathrm{Pb}^{2+}$, respectively.

\subsection{Amine functionalization of the device}

The chemisorption of APTES gave thin films of poly(3-aminopropyltriethoxysilane) of about $1 \mathrm{~nm}( \pm 10 \%)$ thick by ellipsometry. The water contact angle value of these aminopropyl modified silica surfaces was $64^{\circ}( \pm 3 \%)$ in accordance with the literature [14].

The surface density of primary amines on the APTES layer was determined by the Kaiser's test. The calibration of the technique described in the paragraph 2.6.1 allowed determining the 
molar extinction coefficient of the chromophore: $\varepsilon_{570}=4250 \mathrm{~cm} \cdot \mathrm{L} \cdot \mathrm{mol}^{-1}$. Based on this value, the surface density of the primary amine groups of the APTES layer is estimated to $10^{-10} \mathrm{~mol} . \mathrm{mm}^{-2}$.

A quantitative and qualitative analysis was also conducted by XPS. Figure 4.a shows the $\mathrm{N}$ 1s photoelectron spectrum collected for the APTES layer. The N 1s main peak $(399.6 \pm 0.1 \mathrm{eV})$ is resolved in two Gaussian peaks (I) and (II) located at $399.3 \pm 0.1$ and $400.8 \pm 0.1 \mathrm{eV}$. According to other authors [33, 36-39], these positions were attributed to $\mathbf{C}-\mathbf{N}$ and $\mathrm{H}_{2} \mathbf{N}-\mathrm{C}$ - bonds, respectively. The component $(400.8 \pm 0.1 \mathrm{eV})$ represents only $34.7 \%$ of the nitrogen composition. This means that a reticulation process involving nitrogen occurred during the film formation despite the nanometric thickness of the film. Nevertheless the third of nitrogen (corresponding to a density surface of $10^{-10} \mathrm{~mol} \cdot \mathrm{mm}^{2}$ ) is still available as primary amines for the further grafting of the thiourea sensitive molecule. Note that the atomic composition of the layer in $\mathrm{N}$ is 5.8 at. \%.

\subsection{Characterization of the grafting of the ligand}

The monitoring of the grafting of the ligand (5) to terminal amino groups by amide coupling was obtained by UV-visible spectrometry (Jasco V570, Jasco - Japan), ellipsometry, water contact angle measurements and XPS.

The spectroscopy study of the grafting was carried out on APTES thin film immobilized on a quartz slide, used as model surface. In these conditions the maximum absorbance wavelength of the sensitive molecule (5) was $282 \mathrm{~nm}$ (in $\mathrm{CH}_{2} \mathrm{Cl}_{2}$ ). The BOP activation of molecule (5) leads to a shift of the maximum absorbance wavelength $(317 \mathrm{~nm})$ (Table 1) because of the withdrawing effect linked to BOP aromatic groups. On the other hand, $\lambda_{\max }$ of the grafted molecule is shifted to $299 \mathrm{~nm}$ as excepted because the electron inductive withdrawing effect of the amide bond is less important than in the case of the BOP activated molecule.

The grafting of the aromatic sensitive molecule was also proved by the increase of the water contact angle after the coupling reaction on the hydrophilic APTES surface and by the increase of the thickness of the grafted silicon wafer $(+0.3 \mathrm{~nm} \pm 10 \%)$ (Table 2). 
In the present paper, XPS was also employed as an effective technique for following the thiourea grafting on the APTES surface. The presence of $\mathrm{S}$ or to a better extent $\mathrm{N}$ component is an excellent indicator of the grafting. The $\mathrm{S} 2 \mathrm{p}_{1 / 2,3 / 2}$ photoelectron line located at about $165.0 \mathrm{eV}$ can be attributed to the presence of S-C bonds [33-35] (spectrum not shown). The chemical composition measured from the $S 2 p_{1 / 2,3 / 2}$ is $1.15 \%$. The grafting rate can be calculated assuming that one ligand reacts with one primary amine. Moreover as one ligand contains only one sulphur atom the grafting rate is the ratio between the amount of $\mathrm{S}$ over the amount of primary amines before grafting. The atomic composition of the layer in $\mathrm{N}$ before grafting was $5.8 \%$. The primary amine functions represented $34.7 \%$ of the total quantity of $\mathrm{N}$ that gave $2.01 \%$ of primary amine on the surface. Based on XPS analysis the grafting rate of the thiourea was then $57.2 \%$.

Figure 4.b shows the N 1s photoelectron spectrum collected for the APTES grafted sample. The XPS results were compared to those collected from Figure 4.a the N 1s main peak shifts toward high binding energies $(+0.8 \mathrm{eV})$ at about $400.4 \pm 0.1 \mathrm{eV}$. The $\mathrm{N}$ 1s feature is resolved in two Gaussian peaks (I) $(399.3 \pm 0.1 \mathrm{eV}: \mathrm{C}-\mathrm{N}$ [36-39]) and (II) $(401.0 \pm 0.1 \mathrm{eV}: \mathrm{C}-\mathrm{HN}-\mathrm{C}$ [40,41], C$\mathrm{NH}_{2}$ bonds [36-38] and amide functions [34-36]). These positions (I) and (II) are close to those observed in fig. 4a for the APTES layer. However, the position of the component (II) (fig. 4b) located at $401.0 \mathrm{eV}$ is shifted to high binding energy $(+0.2 \mathrm{eV})$. Its intensity and FWHM increase with decreasing the intensity of the $\mathrm{C}-\mathrm{N}$ bonds component. These results indicate the presence of amine and amide functions (additional contribution) corresponding to the grafting process. The nitrogen composition of the layer is then increased $(6.97 \%$ for the APTES grafted film and $5.8 \%$ for the APTES raw film) because of the contribution of the nitrogen atoms of the chelating molecule and the component located at $401.0 \pm 0.1 \mathrm{eV}$ represents now $69.0 \%$ of the $\mathrm{N} 1 \mathrm{~s}$ photoelectron peak (i.e. $4.8 \%)$.

\subsection{Physical properties of the multi-layer oscillator systems}

\subsubsection{Oscillating properties}


For a correct operation of oscillator systems, the losses of the acoustic guided SH-SAW wave generated by the multi-layer structure must be lower than $40 \mathrm{~dB}$ (in air) and $50 \mathrm{~dB}$ (in liquid) to get an open loop gain greater than or equal to 1 (compensation between the sensor losses and the amplifier gain). Insertion losses of $30 \mathrm{~dB}$ were measured, by means of network analyzer, before functionalization (results not shown). After APTES functionalization and grafting, insertion losses increased slightly but remained correct in air (maximum increase of $4 \%$ from $30 \mathrm{~dB}$ (raw device) to $31.3 \mathrm{~dB}$ (functionalized device) at $118.1 \mathrm{MHz}$ ) (Fig. 5). The increasing of the insertion losses of the functionalized device was still correct in liquid (maximum increase of $4 \%$ from $31.3 \mathrm{~dB}$ (in air) to $32.7 \mathrm{~dB}$ (in liquid) at $118.1 \mathrm{MHz}$ ) ensuring a good operation of the oscillator system (Fig. 5). Electrical characterization also allowed measuring the linearity of the phase versus frequency which is typical of a delay line acoustic wave device and necessary for oscillator operation. After functionalization and grafting on the acoustic transducer surface, the phase remained linear (results not shown).

These electrical characterizations allowed checking the sensors performances after the functionalization step. As the total gain of the oscillator system is lower than the upper limit of $50 \mathrm{~dB}(32.7 \mathrm{~dB})$ it is possible to operate the devices equipped with sensitive layer in oscillator configuration and thus to test them in liquid media.

\subsubsection{First attempt of sensitivity in liquid media}

Figure 6 illustrates the frequency shift of the system under flow conditions in presence of $\mathrm{Cd}^{2+}(0.01 \mathrm{M})$. We note a decrease of the frequency of $1000 \mathrm{~Hz}+/-80 \mathrm{~Hz}$, which can be mainly due to the mass effect related to the complexation of $\mathrm{Cd}^{2+}$ by the grafted thiourea. Table 3 resumed the values obtained for different additions of cadmium. The frequency shifts due to the second and the third $\mathrm{Cd}^{2+}$ additions are less important than the first one $(-160 \mathrm{~Hz}+/-80 \mathrm{~Hz}$ and $-140 \mathrm{~Hz}+/-80 \mathrm{~Hz}$, respectively) and non significant (Table 3).

The mass loading $\Delta m(\mathrm{~kg})$ can be deduced from the frequency shift using Eqn 4 [42]: 
$\Delta m=\frac{\Delta F}{F^{\circ}} \times \frac{A}{S_{m}^{V}}$

where $\Delta F$ is the frequency shift $(\mathrm{Hz}), F^{\circ}$ the working frequency $(\mathrm{Hz})\left(\right.$ i.e. $\left.11910^{6} \mathrm{~Hz}\right), A$ the active surface $\left(\mathrm{m}^{2}\right)\left(\right.$ i.e. $\left.210^{-6} \mathrm{~m}^{2}\right)$ and $S_{m}^{V}$ the mass effect sensitivity $\left(\mathrm{m}^{2} \cdot \mathrm{kg}^{-1}\right)$ (i.e. $30 \mathrm{~m}^{2} \cdot \mathrm{kg}^{-1}$ at $118.110^{6}$ $\mathrm{Hz})$.

The mass loading is given Table 3 assuming the mass effect sensitivity of the raw and the functionalized transducers are identical. The amount of complexing sites, involved in the complexation reaction, was also calculated according to the primary amine surface density determined by the Kaiser method $\left(10^{-10} \mathrm{~mol} . \mathrm{mm}^{-2}\right)$, the grafting yield determined by XPS (57.2\%) and the stoechiometry of the complex determined by polarography study (2:1). Based on these results the occupation sites rate is $8.8 \%$ after the first cadmium addition (Table 3 ).

The previous hypothesis of $\mathrm{Cd}^{2+}$ immobilization on the functionalized layer is corroborated by the frequency shift of the device in the presence of a strong $\mathrm{Cd}^{2+}$ chelating agent (i.e. EDTAsolution: $0.01 \mathrm{M})$ (Table 3): an increase of the frequency $(+300 \mathrm{~Hz})$ is recorded after a rinsing time of 90 minutes with the EDTA solution. This frequency shift is due to the extraction of the metal. We note that a rinsing time of 10 minutes is not enough to observe a significant effect and that after 90 minutes the initial frequency is not totally recovered (i.e. the $\mathrm{Cd}^{2+}$ extraction is not completed) definitely because of the high stability of the chelate formed between $\mathrm{Cd}^{2+}$ and the grafted thiourea.

Based on these experiments we can conclude that the low amount of complexing sites, involved in the complexation reaction, is due to a bad accessibility of the ligand rather than a low stability of the thiourea/ $/ \mathrm{Cd}^{2+}$ complex. This bad accessibility of the ligand can be either due to intramolecular hydrogen bonds (blocking the complexing sites) or to a poor mobility of the chelating agent. To improve this last point, the grafting of a spacer is now considering. 


\section{Conclusion}

The chemisorption of APTES is an efficient method to functionalize the top-layer of a Shear Horizontal - Surface Acoustic Wave (SH-SAW) transducer in view of the preparation of sensitive films for applications in liquid media. The reaction took place on the hydroxylated surface of the silica top layer of the SAW device and led to the synthesis of 3D networked polymer films $(\sim 1 \mathrm{~nm}$ thick) with active amino groups available for amide coupling. This corresponds to coverage between one and two monolayers.

A thiourea-based chelating agent leading to stable (2:1) chelates with cadmium and lead in solution was synthesized. Solid state UV-vis spectroscopy, ellipsometry, water contact angle measurements and XPS proved that the molecule was successfully grafted on the 3D-networked amino substrate.

The monitoring of the acoustic losses of the SH-SAW device was carried out in air and in solution. For the multi-layer system it has been shown the increasing of looses after the multi-steps functionalization are low enough (i.e. $+4 \%$ ) to be in accordance with acoustic measurements in liquid media.

The device, functionalized with the thiourea, has been inserted in a microfluidic system. First results have shown a response of the device to a $\mathrm{Cd}^{2+}$ addition (i.e. a decrease of the frequency) due to the chelating effect of the sensitive layer functionalized with the thiourea. The decomplexation process occurs in presence of EDTA (i.e. an increase of the frequency) showing the reversibility of the system. Works are in progress to determine the sensitivity and the selectivity of the system towards $\mathrm{Cd}^{2+}$.

\section{Acknowledgments}

Authors thank Eddy Petit for his help in spectroscopy measurements, Emmanuel TronelPeyroz for wettability studies, Vincent Rouessac for ellipsometry and Frederic Pichot for the deposits of gold layers. Authors also thank Véronique Conedera and Monique Benoît from LAAS- 
CNRS Laboratory (UMR CNRS 8001) in Toulouse for the fabrication of the guided SH-SAW devices in the frame of the National Network of Large Technology Centers for Basic Technologic Research.

\section{References}

[1] F. Razan, C. Zimmermann, D. Rebière, C. Déjous, J. Pistré, M. Destarac and B. Pavageau, Sens. Actuators, B, 108 (2005) 917.

[2] M. J. Vellekoop, Ultrasonics, 36 (1998) 7.

[3] J. Du, G. L. Harding, A. F. Collings and P. R. Dencher, Sens. Actuators, A, 60 (1997) 54.

[4] D. Rebière, C. Déjous, J. Pistré, R. Planade, J. F. Lipskier and P. Robin, Sens. Actuators, B, 43 (1997) 35.

[5] E. Gizeli, F. Bender, A. Rasmusson, K. Saha, F. Josse and R. Cernosek, Biosens. Bioelectron., 18 (2003) 1399.

[6] S. Casilli, C. Malitesta, S. Conoci, S. Petralia, S. Sortino, L. Valli, Biosens. Bioelectron., 20 (2004) 1190.

[7] G.S. Huang, M.-T. Wang, C.-W. Su, Y.-S. Chen, M.-Y. Hong, Biosensors and Bioelectronics, 23 (2007) 319.

[8] J. Yin, W. Wei, X. Liu, B. Kong, L. Wu, S. Gong, Anal. Biochem., 360 (2007) 99.

[9] E. Otazo-Sánchez, L. Pérez-Marín, O. Estévez-Hernández, S. Rojas-Lima and J. AlonsoChamarro, J. Chem. Soc., Perkin Trans. 2, (2001) 2211.

[10] E. P. Pluedemann, Silane Coupling Agents; Plenum Press: New York, (1982).

[11] A. Ulman, Ultrathin Organic Films; Academic Press: New York, (1991).

[12] S. Flink, F. van Veggel and D. N. Reinhoudt, J. Phys. Org. Chem., 14 (2001) 407.

[13] J. H. Moon, J. W. Shin, S. Y. Kim and J. W. Park, Langmuir, 12 (1996) 4621.

[14] Haller, J. Am. Chem. Soc., 100 (1978) 8050.

[15] E. T. Vandenberg, L. Bertilsson, B. Liedberg, K. Uvdal, R. Erlandsson, H. Elwing and I. 
Lundström, J. Colloid Interface Sci., 147 (1991) 103.

[16] D. K. Kurth, T. Bein, Langmuir, 11(1995) 3061.

[17] A. Simon, T. Cohen-Bouhacina, M. C. Porté, J. P. Aimé, C. Baquey, J. Colloid Interface Sci. 251 (2002) 278.

[18] S. Ek, E. I. Iiskola, L. Niinistö, J. Vaittinen, T. T. Pakkanen, J. Keränen, A. Auroux Langmuir, 19 (2003) 10601.

[19] C. Zimmermann, D. Rebière, C. Déjous, J. Pistré, E. Chastaing and R. Planade, Sens. Actuators, B, 76 (2001) 86.

[20] J. Freudenberg, M. von Schickfus and S. Hunklinger, Sens. Actuators, B, 76 (2001) 147.

[21] A. Manaka, T. Ishii, K. Takahashi and M. Sato, Tetrahedron Lett., 46 (2005) 419.

[22] S. F. Wnuk, S. M. Chowdhury, P. I. Garcia and M. J. Robins, J. Org. Chem., 67 (2002) 1816.

[23] B. T. Cho and S. K. Kang, Tetrahedron, 61 (2005) 5725.

[24] B. Trémillon, Electrochimie analytique et reactions en solution, ed. Masson, Paris, T. 2, ch. 10 (1993).

[25] C. Montalbetti and V. Falque, Tetrahedron, 61 (2005) 10827.

[26] P. S. Ramamoorthy and J. Gervay, J. Org. Chem., 62 (1997) 7801.

[27] V. K. Sarin, S. B. H. Kent, J. P. Tam and R. B. Merrifield, Anal. Biochem., 117 (1981) 147.

[28] D.A. Shirley, Phys. Rev. B., 5 (1972) 4709.

[29] J.H. Scofield, J. of Electron Spectrosc. and Related Phenom., 8 (1976) 129.

[30] G.C. Smith, J. Electron spectrosc. Related Phenom., 148 (2005) 21.

[31] M.P. Seah, in Practical Surface Analysis (2nd edn), vol. 1, D. Briggs and M.P. Seah (eds) J. Wiley \& Sons, N.Y. (1993) 543.

[32] N. Moll, C. Déjous, D. Rebière, J. Pistré, R. Planade, Proceedings of DCIS2004, Bordeaux, November 2004, 276.

[33] K. Iketaki, K. Kanai, K. Tsuboi, W. Fujita, K. Awaga, M. Knupfer, Y. Ouchi, K. Seki, Synthetic Metal, 153 (2005) 457. 
[34] T.H. Ko, H. Chu, Spectrochimica Acta part A, 61 (2005) 3353.

[35] C.D. Wagner, V.M. Riggs, L.E. Davis, J.F. Moulder, G.E. Muilenberg, In : Handbook of X-ray Photoelectron Spectroscopy, Perkin-Elmer, Published by: Physical Electronics Division, Eden Prairie, MN, (1979).

[36] H.J. Martin, K.H. Schultz, J.D. Bumgardner and K.B. Walters, Langmuir, 23 (2007) 6645.

[37] G. Qinlin, C. Xianhua, Appl. Surf. Sci, 253 (2007) 6800.

[38] F. Pippig, A. Hollander, Appl. Surf. Sci, 253 (2007) 6817.

[39] Z.Q. Wei, C. Wang, C.F. Zhu, C.Q. Zhou, B. Xu, C.L.Bai, Surf. Sci, 45 (2000) 401.

[40] M. Minier, M. Salmain, N. Yacoubi, L. Barbes, C. Methivier, S. Zanna, C.M. Pradier, Langmuir, 21 (2005) 5957.

[41] P.J. Tarcha, L. Salvati, R.W. Johnson, Surf. Sci. Spectra , 8 (4) (2001) 312.

[42] N. Moll, E. Pascal, D-H. Dinh, J-P. Pillot, B. Benneteau, D. Rebière, D. Moynet, Y. Mas, D. Mossa-layi, J. Pistré, C. Déjous, Sens. Actuators, B, 22 (2007) 2145. 


\section{Figure captions}

Figure 1: Working scheme presenting the different steps of the preparation of the sensitive layer. Step 1: chemical deposition of the APTES layer on the $\mathrm{SiO}_{2}$ guiding layer; Step 2: grafting of the chelating agent through amide bond on the primary amine functions; Step 3: illustration of the chemical recognition of the metal by the thiourea-based chelating agent.

Figure 2: Experimental setup: the volume of the microcell defined between the outlet and inlet tubes is $500 \mu \mathrm{L}$. The functionalized surface in contact with the solution is $2 \mathrm{~mm}^{2}$.

Scheme 1: Synthesis of the chelating molecule based on $\alpha$-thiourea: i) $\mathrm{NaBH}_{3} \mathrm{CN}, \mathrm{H}_{3} \mathrm{BO}_{3}$, benzaldehyde, methanol, 1 h., r.t.; ii) KSCN, acetone, 1 h., reflux; iii) 2, acetone, 30 min., reflux; iv) $\mathrm{NaOH}(1 \mathrm{~N})$, methanol, 4 h., $0^{\circ} \mathrm{C}$ to r.t.

Scheme 2: Scheme of the ligand grafting on terminal amino groups: i) $\mathrm{BOP}, \mathrm{HOBt}, \mathrm{DIEA}, \mathrm{CH}_{2} \mathrm{Cl}_{2}$, overnight, r.t.

Figure 3: Example of polarographic curves obtained during a reduction scan in absence $\left(\mathrm{a}-\mathrm{Cd}^{2+}=\right.$ $\left.5.10^{-5} \mathrm{M}\right)$ and in presence of the chelating molecule $\left(\mathrm{b}-\mathrm{Cd}^{2+}: 5.10^{-5} \mathrm{M}\right.$ and chelating agent: $1.10^{-4}$ $\mathrm{M})$.

Figure 4: Spectrum of photoelectrons N 1s collected on the a) APTES film and b) APTES grafted film.

Figure 5: Electrical characterization of the guided SH-SAW device after functionalization by APTES and the thiourea in air and in liquid (minimum losses in air: $-31.276 \mathrm{~dB}$; minimum losses in 
liquid: $-32.687 \mathrm{~dB}$ ). The losses of the device before functionalization are $30 \mathrm{~dB}$ in air (representation not shown).

Figure 6: Frequency shift due to a $\mathrm{Cd}^{2+}$ mass loading. (y-scale is relative to the initial frequency: $118114286 \mathrm{~Hz})$. 


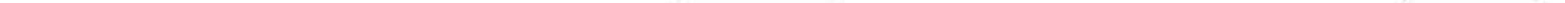




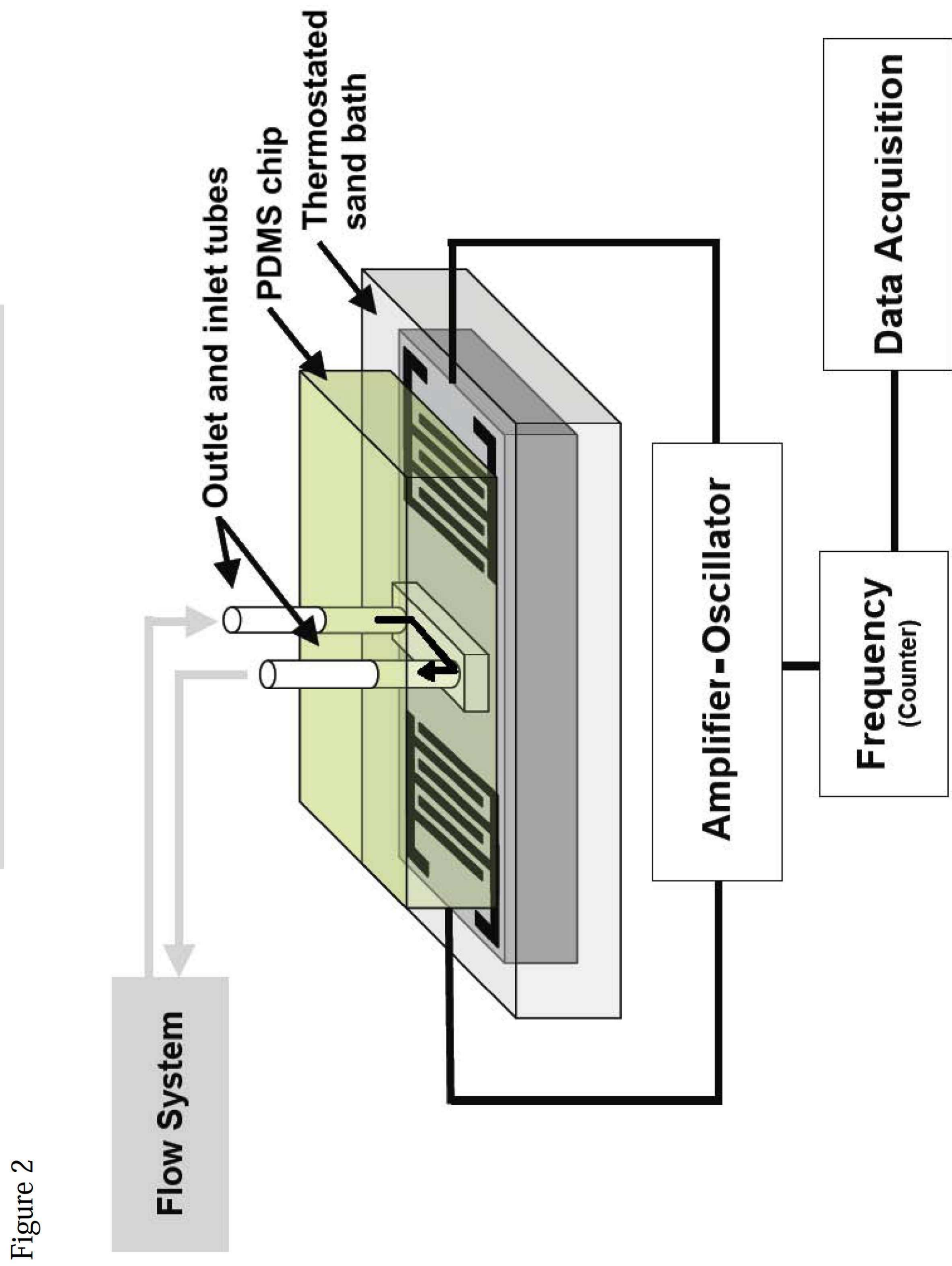


Scheme 1
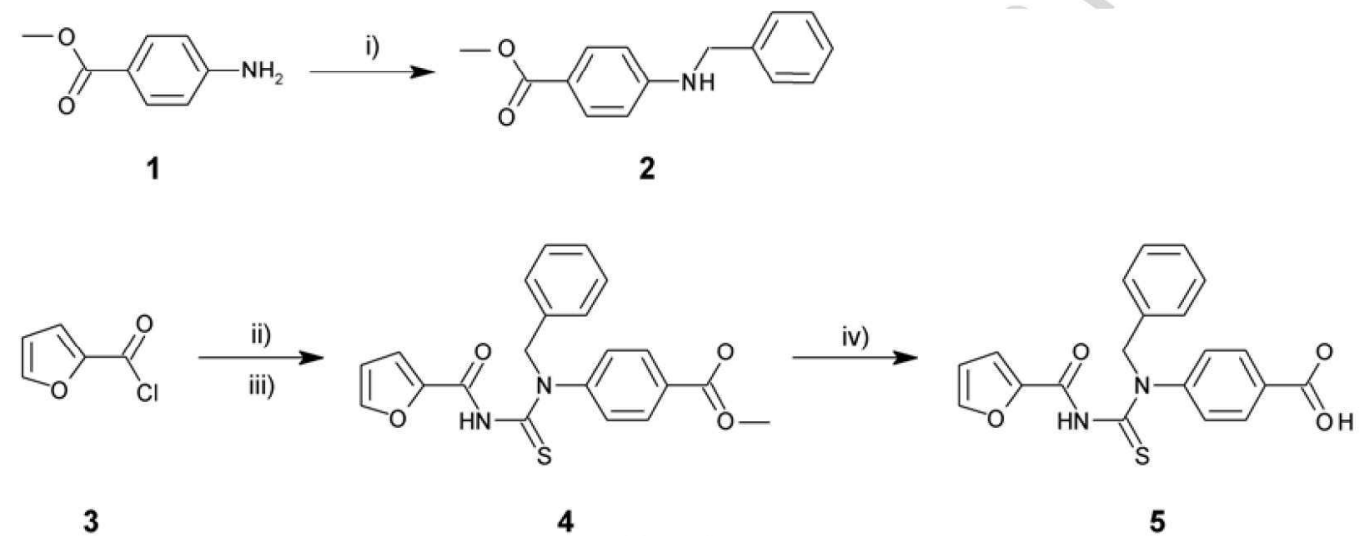
Scheme 2

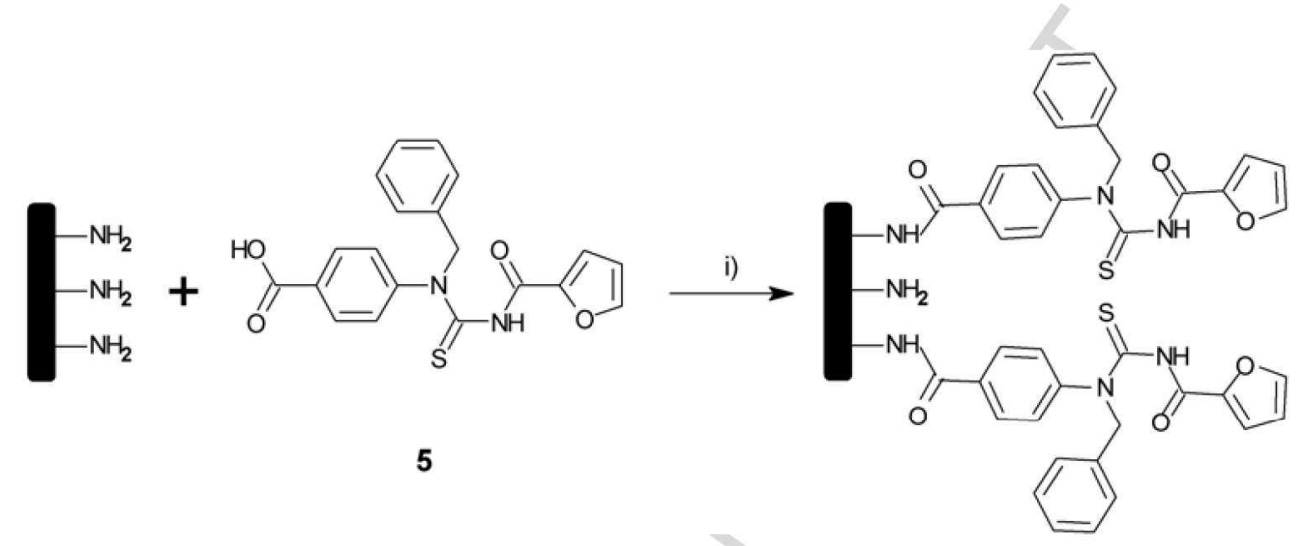


Figure 3

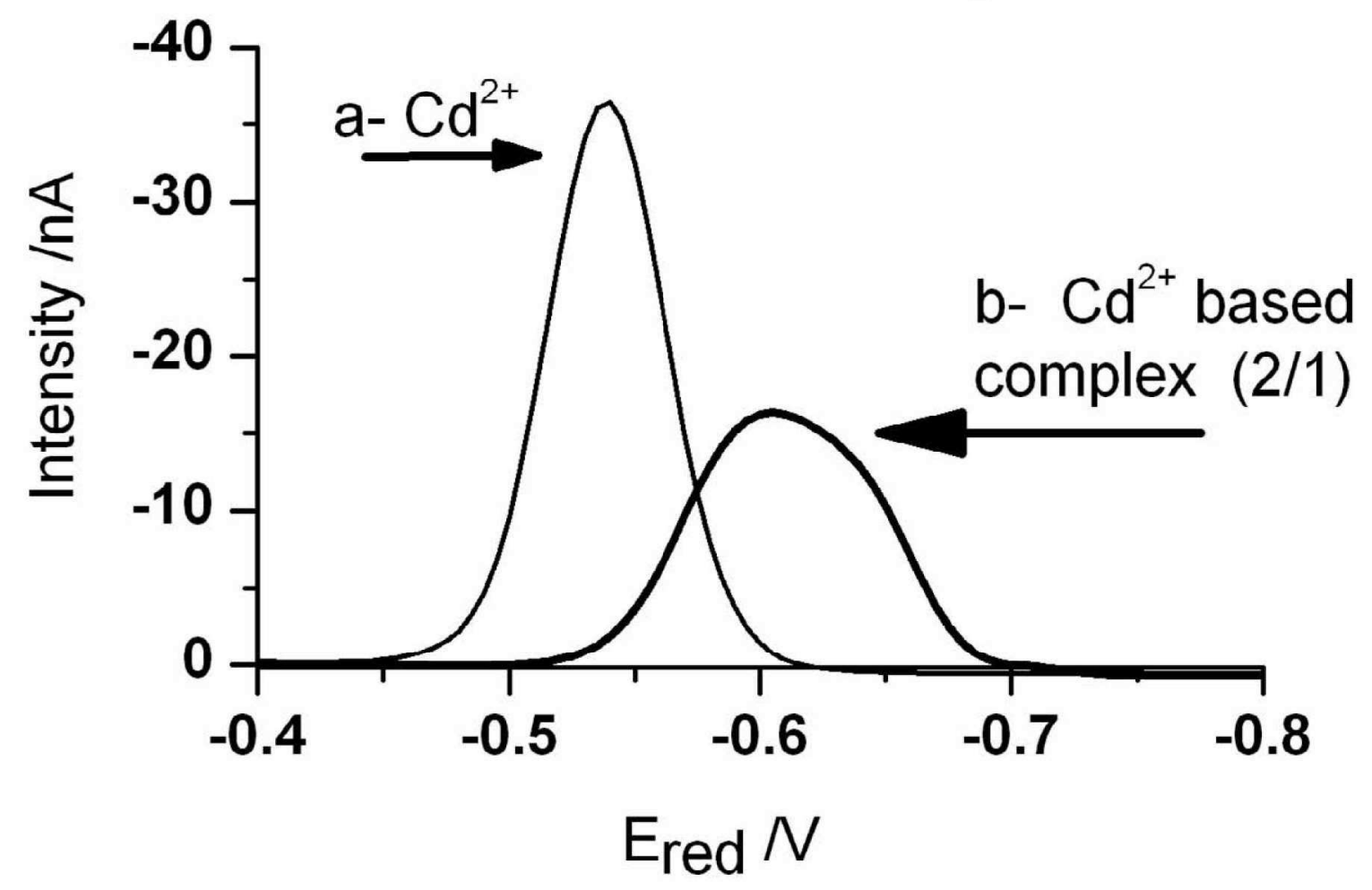


Figure 5

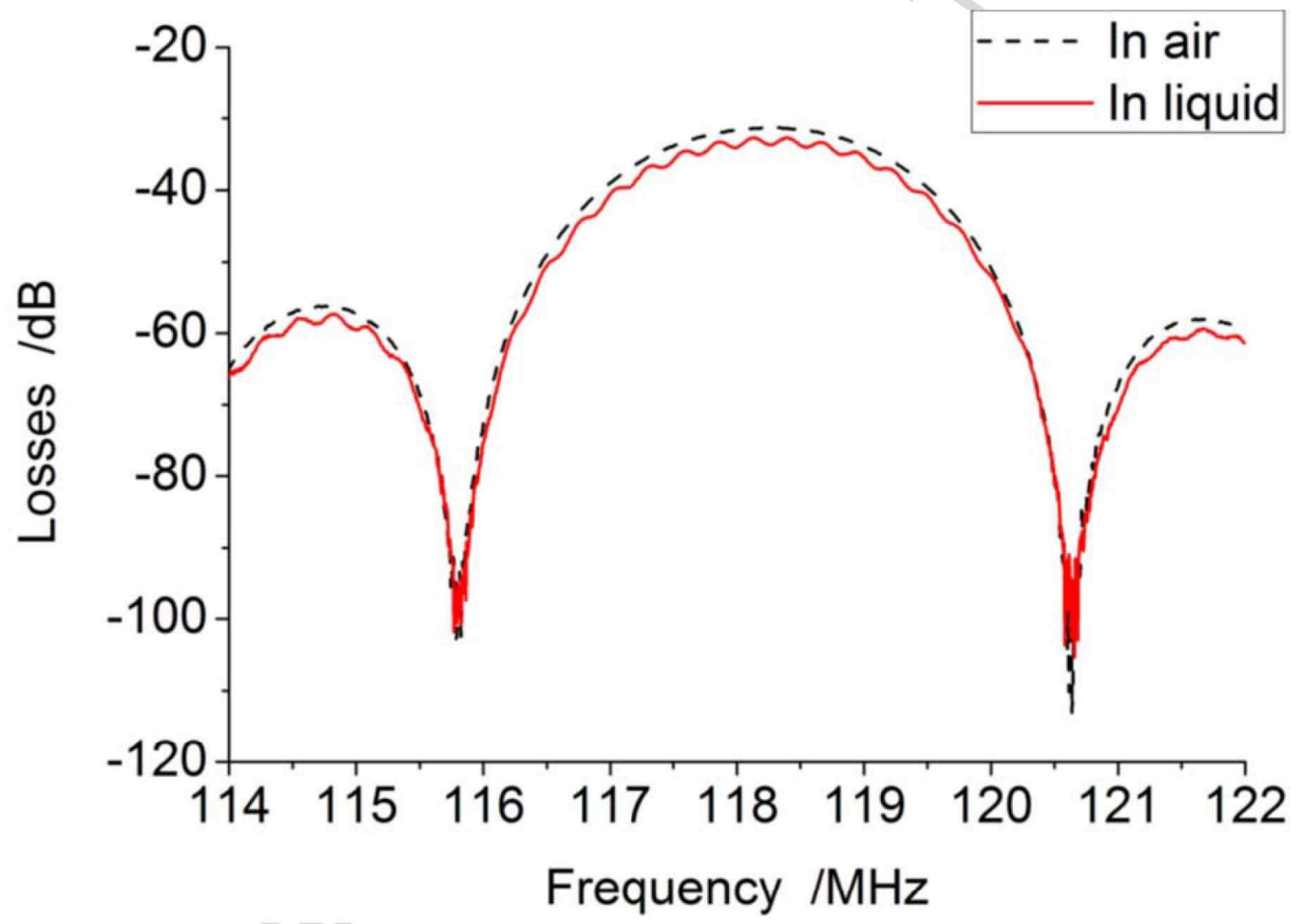


Figure 6

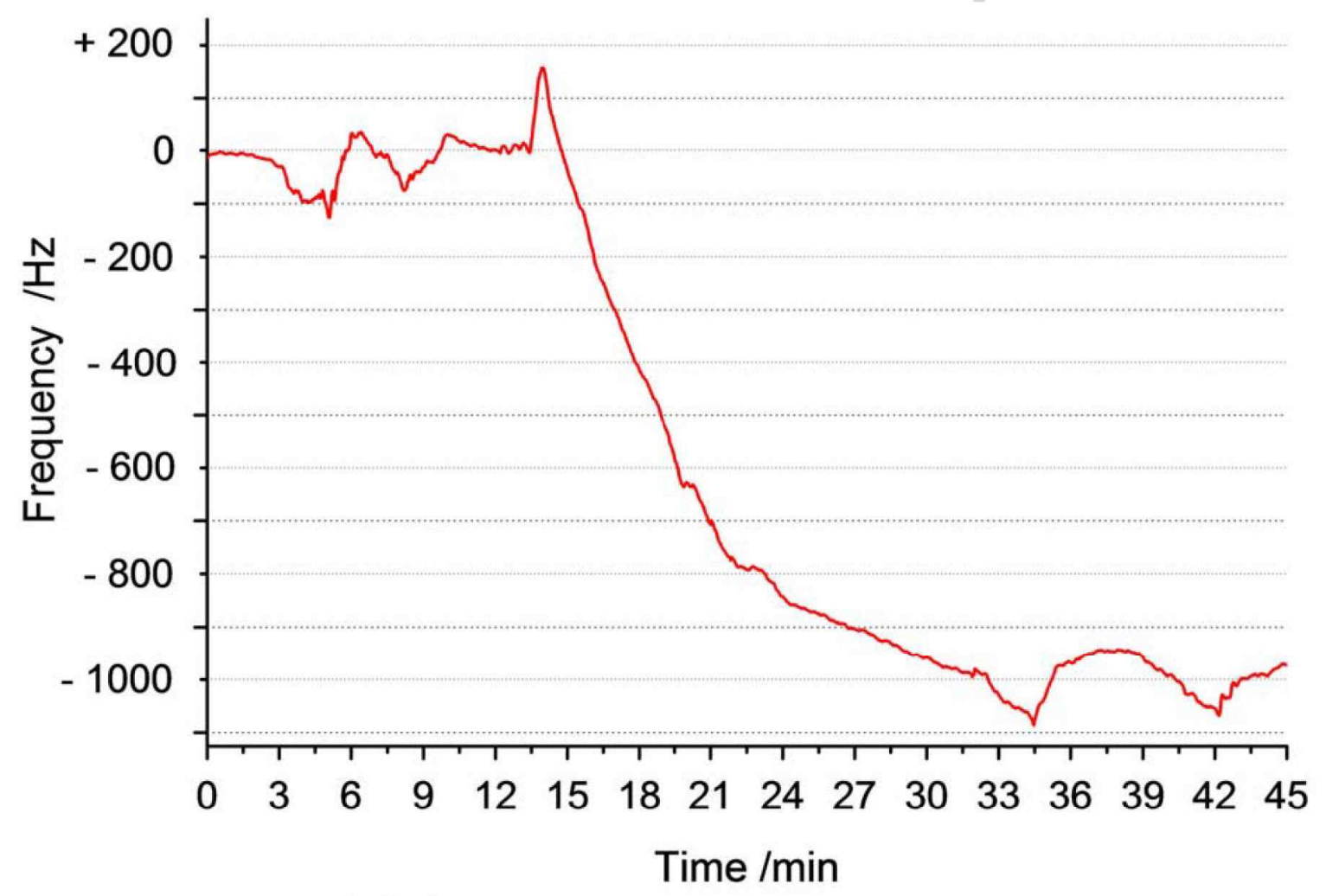


Table 1: Maximum absorbance wavelength of the sensitive molecule $\mathbf{5}$ as a function of its state (raw, activated by BOP and grafted by amide bond).

\begin{tabular}{rc}
\hline & $\lambda_{\max } / \mathrm{nm}$ \\
\hline Chelating molecule $\mathbf{5}$ & 282 \\
\hline $\mathbf{5}$ activated by BOP & 317 \\
$\mathbf{5}$ grafted & 299 \\
\hline
\end{tabular}


Table 2: Ellipsometry and wettability study of the grafted surface.

\begin{tabular}{rcc}
\hline & Thickness $/ \mathrm{nm}$ & $\theta_{\text {contact }}$ \\
\hline APTES blank & 1.0 & $64^{\circ}$ \\
APTES grafted with 5 & 1.3 & $71^{\circ}$ \\
\hline
\end{tabular}


Table 3: Monitoring of frequency shifts recorded for different $\mathrm{Cd}^{2+}$ additions. Theses shifts are correlated with the mass loading variation and the filled site rates.

\begin{tabular}{rccc}
\hline & $\begin{array}{c}\Delta \mathrm{f} / \mathrm{Hz} \\
(+/-80 \mathrm{~Hz})\end{array}$ & $\begin{array}{c}\Delta \mathrm{m} / \mathrm{ng} \\
(+/-0.05 \mathrm{ng})\end{array}$ & $\begin{array}{c}\text { Cumulated \% of } \\
\text { filled sites }\end{array}$ \\
\hline First cadmium addition & $\mathbf{- 1 0 0 0}$ & $+\mathbf{0 . 5 6}$ & $\mathbf{8 . 8}$ \\
Second cadmium addition & -160 & +0.09 & 10.2 \\
Third cadmium addition & -140 & +0.08 & $\mathbf{1 1 . 4}$ \\
\hline 10 minutes rinse by EDTA & +80 & -0.05 & 10.6 \\
90 minutes rinse by EDTA & +300 & -0.17 & $\mathbf{7 . 9}$ \\
\hline
\end{tabular}

